\title{
Tobacco habituated and non-habituated subjects exhibit different mutational spectrums in head and neck squamous cell carcinoma
}

\author{
Rakesh M. Rawal • Madhvi N. Joshi • Poonam Bhargava • Inayat Shaikh • \\ Aanal S. Pandit - Riddhi P. Patel - Shanaya Patel - Kiran Kothari · \\ Manoj Shah $\cdot$ Akshay Saxena $\cdot$ Snehal B. Bagatharia
}

Received: 20 October 2014/Accepted: 15 November 2014/Published online: 3 December 2014

(C) The Author(s) 2014. This article is published with open access at Springerlink.com

\begin{abstract}
Head and neck squamous cell carcinoma (HNSCC) is the sixth most common non-skin cancer in the world. Tobacco chewing is implicated with most of the cases of HNSCC but this type of cancer is increasing in non-tobacco chewers as well. This study was instigated to provide comprehensive variant and gene-level data in HNSCC subjects of the Indian population and fill the gap in the literature on comparative assessment of gene mutations in cancer subjects with a habit of tobacco and those without any habit using targeted amplicon sequencing. We performed targeted Amplicon sequencing of 409 tumor suppressor genes and oncogenes, frequently mutated across many cancer types, including head and neck. DNA from primary tumor tissues and matched blood was analyzed for HNSCC patients with a habit of tobacco and those without any habit. PDE4DIP, SYNE1, and NOTCH1 emerged as the highly mutated genes in HNSCC. A total of 39 candidate causal variants in 22 unique cancer driver genes were identified in non-habitual (WoH) and habitual (WH) subjects. Comparison of genes from both the subjects, showed seven unique cancer driver genes (KIT, ATM, RNF213,
\end{abstract}

Electronic supplementary material The online version of this article (doi:10.1007/s13205-014-0267-0) contains supplementary material, which is available to authorized users.

M. N. Joshi · P. Bhargava · I. Shaikh · A. S. Pandit .

R. P. Patel · A. Saxena $\cdot$ S. B. Bagatharia $(\varangle)$

Gujarat State Biotechnology Mission, Department of Science and Technology, Government of Gujarat, 11th Block, 9th Floor, Udyog Bhavan, Gandhinagar 382 011, Gujarat, India

e-mail: snehalbagatharia@ hotmail.com

R. M. Rawal - S. Patel $\cdot$ K. Kothari - M. Shah

Gujarat Cancer and Research Institute, Gujarat Cancer Society, Civil Hospital Campus, Asarwa, Ahmedabad 380 016, Gujarat, India
GATA2, DST, RET, CYP2C19) in WoH, while WH showed five (IL7R, PKHD1, MLL3, PTPRD, MAPK8) and 10 genes (SETD2, ATR, CDKN2A, NCOA4, TP53, SYNE1, KAT6B, THBS1, PTPRT, and FGFR3) were common to both subjects. In addition to this NOTCH1, $\mathrm{NOTCH} 2$, and NOTCH4 gene were found to be mutated only in habitual subjects. These findings strongly support a causal role for tobacco, acting via PI3K and MAPK pathway inhibition and stimulation of various genes leading to oncogenic transformations in case of tobacco chewers. In case of non-tobacco chewers it appears that mutations in the pathway affecting the squamous epithelial lineage and DNA repair genes lead to HNSCC. Somatic mutation in CYP2C19 gene in the non-habitual subjects suggests that this gene may have a tobacco independent role in development and progression of HNSCC. In addition to sharing high mutation rate, NOTCH gene family was found to be mutated only in habitual sample. Further, presence of mutated genes not earlier reported to be involved in HNSCC, suggest that the Indian sub-continent may have different sets of genes, as compared to other parts of the world, involved in the development and progression of HNSCC.

Keywords Head and neck squamous cell carcinoma . Tobacco $\cdot$ Amplicon sequencing $\cdot$ Mutation $\cdot$ Oncogenic transformations

\section{Introduction}

Head and neck squamous cell carcinoma (HNSCC) is the sixth most common non-skin cancer in the world. More than 600,000 cases are reported per year having a mortality rate of approximately $50 \%$ (Bauman et al. 2012; Ferlay 
et al. 2010). India contributes to the highest number of incident cases of oral cancer which approximates to 20-30\% of all cancers (http://wwwicmr.nic.in/cancer.pdf). Tobacco chewing, smoking, ill-fitting dentures, poor oral hygiene, syphilis, inadequate diet (lacking in fruits and leafy vegetables), malnutrition, and chronic irritation from rough or broken teeth are common causes implicated to development of oral cancer. Recently, HNSCC has also been associated with HPV virus (Lechner et al. 2013). Vast majority of HNSCC originate due to tobacco chewing, smoking, and/or alcohol consumption (Zeka et al. 2003). However, there are incidences where people who never chewed tobacco or consumed alcohol have developed oral cancer (Subramanian and Govindan 2007). This indicates involvement of genetic susceptibility as well as a complex interaction of genetic and environmental factors in the etiology of oral cancer (Imyanitov et al. 2004).

In the year 2011, the first ever reports of whole exome sequencing of oral cancer patients were revealed (Agrawal et al. 2011; Stransky et al. 2011). Agarwal et al. (2011) sequenced $\sim 18,000$ protein coding genes in tumors from 32 patients. A total of 911 candidate somatic mutations were identified in 725 genes of 32 tumors. Stransky et al. (2011) identified 130 coding mutations per tumor. The common finding of both the groups included genes such as TP53, CDKN2A, PIK3CA, and NOTCH1 to be the key players in development of HNSCC. TP53 is the most commonly mutated gene in HNSCC (Agrawal et al. 2011; Stransky et al. 2011; Poeta et al. 2007). All these studies majorly focus on HNSCC patients with a habit of tobacco chewing but the $15 \%$ patients without above-mentioned habits and still found to have development of HNSCC (Rodriguez et al. 2004) remain neglected. Till date there are no reports available on the genetic analysis of these types of patients. Hence, the aim of present study was to analyze genes involved in progression and development of HNSCC among tobacco habituated and non-habituated HNSCC subjects and to analyze differences in the mutational pattern among the two groups using Comprehensive Ampliseq cancer panel of Life Technologies on Ion Torrent Platform followed by bioinformatics analysis.

\section{Materials and methods}

\section{Materials}

DNA was derived from tumors and their matched normal peripheral blood derived mononuclear cells (PBMNC) of four patients. The study comprised three samples of four HNSCC patients using both tumor tissues and matched blood. Sample 1 consisted of tumor tissues of one patient without any habit $(\mathrm{WoH})$; sample 2 consisted of tumor tissue of three patients with tobacco chewing habit (WH). Matched blood of both WH and $\mathrm{WoH}$ was taken as control.

Tumor samples from the patients and the matched peripheral blood samples were obtained from the Gujarat Cancer and Research Institute. The demographics and the clinical characteristics of the patient population including age, gender, smoking habit use/exposures were taken as shown in Table 1. Written informed consent was taken from each subject as per institutional guidelines under BioBank Project.

\section{DNA extraction and sequencing}

DNA was isolated from tumor tissue and control blood sample using PureLink ${ }^{\circledR}$ Genomic DNA Extraction Kit (Invitrogen, USA). Qubit ${ }^{\circledR} 2.0$ Fluorometer (Invitrogen, USA) was used to obtain an accurate quantitation of DNA. DNA quality such as ratio of absorbance at 260/280 and 260/230 nm was measured using Nanophotometer (Imlpen, USA). Library was prepared using Ion Express Plus Fragment library kit (Life technologies, USA). DNA was sheared into blunt-ended fragments by enzymatic lysis using Ion Shear Plus Reagents. The fragments are ligated to Ion Xpress $^{\mathrm{TM}}$ Barcode Adapters 1-16, followed by nick-repair to complete the linkage between adapters and DNA inserts. Amplicons were constructed using Ion AmpliSeq ${ }^{\mathrm{TM}} \mathrm{Com}-$ prehensive Cancer Panel (Life technologies, USA) targeting 409 tumor suppressor genes and oncogenes frequently cited and frequently mutated (https://tools.lifetechnologies.com/ content/sfs/brochures/CO25560_Ion_AmpliSeq_Compreh ensive_Cancer_Panel_Gene_List_final9062012.pdf). All three barcoded libraries were mixed together in one equimolar sample and subsequently processed according to the manufacturer's protocol using the Ion Xpress Barcode Adaptor kit and sequenced in the Ion Torrent ${ }^{\mathrm{TM}}$ Personal Genome Machine ${ }^{\mathrm{TM}}\left(\mathrm{PGM}^{\mathrm{TM}}\right)$ using an Ion $318^{\mathrm{TM}}$ chip and the Ion Sequencing Kit (300 bp chemistry).

Data analysis

Reads were mapped onto human hg19 reference genome and quality was assessed by filtering polyclonal and noisy reads, clipping adapters, and low quality reads in Torrent Suite Software 3.4.1 on Ion PGM Torrent Server (http:// products.invitrogen.com/ivgn/product/4477685). Barcoded samples were separated and SNVs, insertions and deletions were called using the recommended Torrent Variant Caller 3.6 Plug-in (http://mendel.iontorrent.com/ion-docs/ Torrent+Variant+Caller+Plugin.html) with default preset parameters, optimized for ion AmpliSeq comprehensive cancer panel.

Ion Reporter software was used for automated variant annotation derived from public databases (dbSNP, 
COSMIC, Ensemble, RefSeq) (https://ionreporter. lifetechnologies.com/ir/), which produce classified and annotated variants calls. Ingenuity Variant Analysis software, integerated in the Ion reporter software was used for identification of causal variants and its association with the disease. Low quality variants were filtered out with base call quality $<20$, to keep only high quality variants. Variants in each sample were compared using online VENNY tool (http://bioinfogp.cnb.csic.es/tools/venny/) to classify into germline and somatic variants.

Non-coding, intronic, and UTR variants were filtered out to keep only coding and splice site variants. Annotated variants found in dbSNP (Sherry et al. 2001) were identified as known variants and variants found in COSMIC database (Bamford et al. 2004) were identified as cancer associated variants. Novel variants were subjected to Polyphen2 (http://genetics.bwh. harvard.edu/pph2/) and SIFT (http://sift.jcvi.org/) software, integrated in ingenuity variant analysis tool for prediction of possible damaging functional effects of variants.

\section{Results}

To accomplish the purpose of the study, three samples from four HNSCC subjects were taken. Sample 1 consisted of tumor tissues of cancer subject without any habit (hereafter referred to as $\mathrm{WoH})$, sample 2 that of subjects with smoking and tobacco chewing habit (hereafter referred to as WH), and sample 3 matched normal lymphocytes of sample 1 and 2 which served as control. All three samples were subjected to targeted amplicon sequencing using Ampliseq Comprehensive cancer panel of Life Technologies on the Ion Torrent Platform.

Reference mapping of reads with human genome (hg19) resulted into $88.6 \mathrm{MB}$ data of 9,61,743 reads for $\mathrm{WoH}$, $119 \mathrm{MB}$ data constituting 12,92,207 reads for $\mathrm{WH}$, and $143 \mathrm{MB}$ of 15,42,354 reads for control as shown in Table 2. An average read length of $110 \mathrm{bp}$ and longest read length of $379 \mathrm{bp}$ was obtained. It was possible to map more than $97 \%$ of reads to target regions with reference genome. High quality reads at $20 \times$ coverage were $88 \%$ for $\mathrm{WoH}, 86 \%$ for $\mathrm{WH}$, and $93 \%$ for control. Mean reads depth coverage was found to be 59.4-fold for WoH, 79.6folds for $\mathrm{WH}$, and 95.5-fold for control, meeting the requirement of obtaining $100 \%$ variant calling sensitivity.

Variant analysis

Further, WoH and WH detected 934 and 959 variations like SNPs, insertions and deletions in 280 and 275 genes, respectively, whereas 1,354 variants in 318 genes detected in control (Table 3 ). Ti/Tv ratio and dbSNP rate of variants was calculated for statistically validating variant calling quality in each sample. Ratio was calculated for the number of transitions to the number of transversions as it is particularly helpful for assessing the quality of SNP calls (Kalavrezos et al. 2012). Ti/Tv ratios of SNPs were found to be 2.51, 2.61, and 2.52 for $\mathrm{WoH}, \mathrm{WH}$, and control samples, respectively, as shown in Table 3. Ti/Tv ratio for novel variants was also calculated and it was found to be 1.0 and 1.4 for $\mathrm{WoH}$ and WH, respectively. Accuracy of variant calling was further validated by calculating dbSNP rate of total variants detected in each sample. About $95 \%$ of variants detected in all three samples were already reported in dbSNP database (dbSNP 129) giving an indication of good quality of variant calling.

Table 2 Reads mapping details showing number of reads mapped, reads mapped on to the target region, coverage, and coverage depth

\begin{tabular}{|c|c|c|c|c|}
\hline Sample & $\begin{array}{l}\text { Mapped } \\
\text { reads }\end{array}$ & $\begin{array}{l}\text { Reads } \\
\text { on } \\
\text { target } \\
(\%)\end{array}$ & $\begin{array}{l}20 \times \text { coverage } \\
(\%)\end{array}$ & $\begin{array}{l}\text { Mean } \\
\text { coverage } \\
\text { depth } \\
\text { (fold) }\end{array}$ \\
\hline $\begin{array}{l}\text { Sample } 1 \\
(\mathrm{WoH})\end{array}$ & $\begin{array}{l}(88.6 \mathrm{MB}) \\
9,61,743 \text { reads }\end{array}$ & 97.35 & 88.91 & 59.4883 \\
\hline $\begin{array}{l}\text { Sample } 2 \\
\text { (WH) }\end{array}$ & $\begin{array}{l}(119 \mathrm{MB}) \\
12,92,207 \text { reads }\end{array}$ & 97.47 & 86.23 & 79.6575 \\
\hline $\begin{array}{l}\text { Sample } 3 \\
\quad \text { (control) }\end{array}$ & $\begin{array}{l}(143 \mathrm{MB}) \\
15,42,354 \text { reads }\end{array}$ & 97.61 & 93.80 & 95.5884 \\
\hline
\end{tabular}

Table 1 Demographic, histopathological, and clinical details of patients taken for this study

\begin{tabular}{|c|c|c|c|c|c|c|c|c|}
\hline $\begin{array}{l}\text { Subject } \\
\text { type }\end{array}$ & Gender & Age & $\begin{array}{l}\text { Ethnic } \\
\text { group }\end{array}$ & $\begin{array}{l}\text { Tobacco } \\
\text { chewing }\end{array}$ & Smoking & Alcohol & Tumor site & Histopathological examination \\
\hline WoH & Male & 45 & Indian & - & - & - & $\begin{array}{l}\text { Right lateral border of } \\
\text { the tongue }\end{array}$ & $\begin{array}{l}\text { Well to moderately differentiated squamous } \\
\text { cell carcinoma }\end{array}$ \\
\hline WH & Male & 47 & Indian & + & + & + & $\begin{array}{l}\text { Left lateral border of the } \\
\text { tongue }\end{array}$ & $\begin{array}{l}\text { Well differentiated keratinizing squamous cell } \\
\text { carcinoma }\end{array}$ \\
\hline WH & Male & 51 & Indian & + & - & - & $\begin{array}{l}\text { Left lateral border of the } \\
\text { tongue }\end{array}$ & $\begin{array}{l}\text { Well differentiated squamous cell carcinoma } \\
\text { of level grade-I }\end{array}$ \\
\hline WH & Male & 40 & Indian & + & - & - & Left tongue & $\begin{array}{l}\text { Moderately differentiated keratinizing } \\
\text { squamous cell carcinoma }\end{array}$ \\
\hline
\end{tabular}



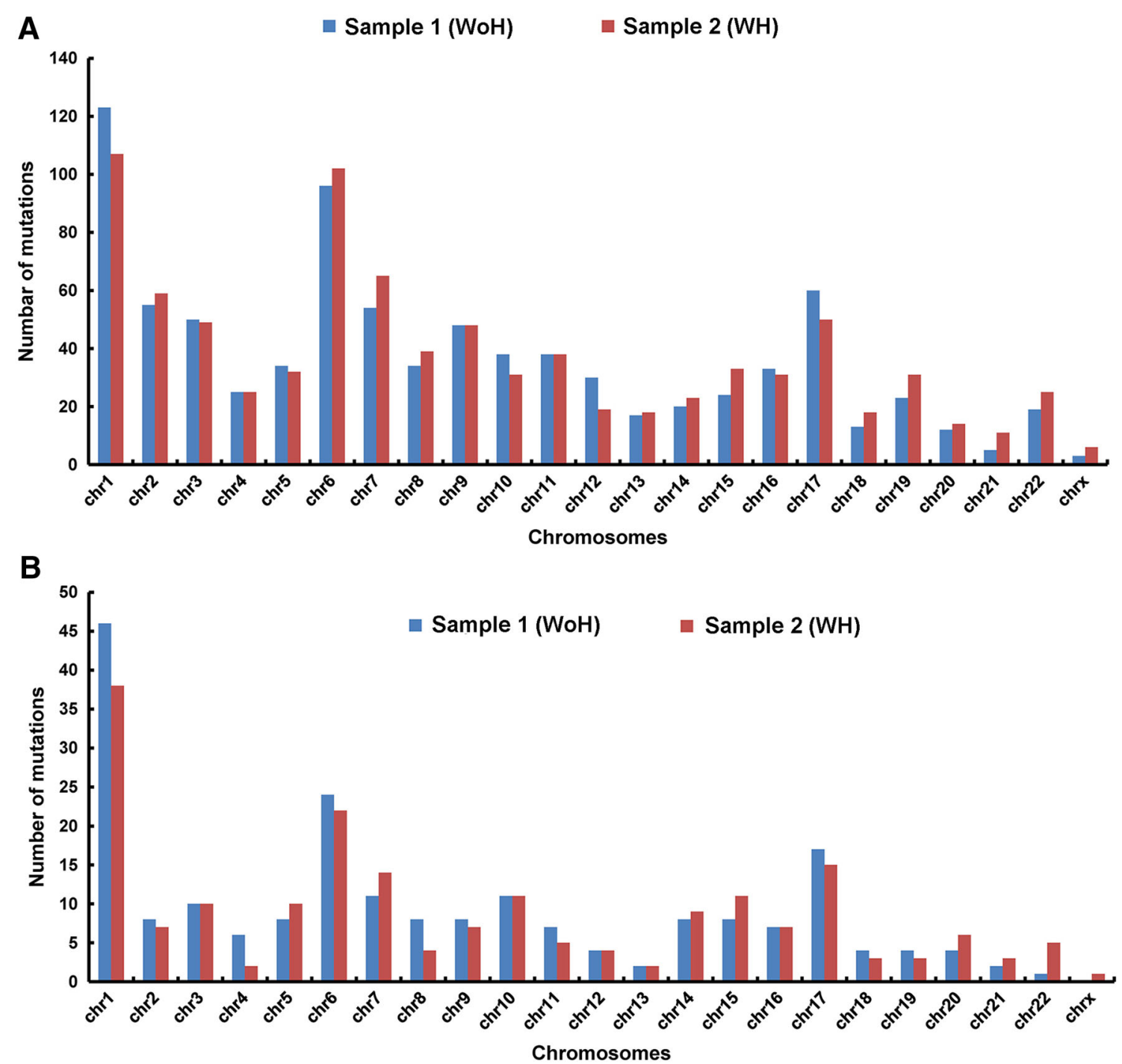

Fig. 1 Graph showing variant distribution across all chromosomes (a) non-filtered (b) filtered (variants with a call quality $>20$ and only were in exonic and non-synonymous)

\section{Chromosomal distribution of variants}

Chromosome 1, 6, and 17 were found to have highest number of variants compared to other chromosomes (Fig. 1a). In order to examine whether this pattern was coincidental or consistent, the variants that were present in the exonic regions leading to non-synonymous mutation were only considered. As can be seen in Fig. 1b, the frequency distribution of exonic non-synonymous variants was similar to the non-filtered variants across the chromosomes indicating consistency in both findings.

Detection of cancer driver variants and genes

A total of 934 and 959 variants were found in $\mathrm{WoH}$ and WH, respectively, of which 852 and 870 qualified the confidence criteria (call quality $>20$ ). Further, 525 variants from $\mathrm{WoH}$ and 516 from $\mathrm{WH}$, corresponded to exonic regions, of which 207 and 198, respectively, were nonsynonymous (Fig. 2).

Of the non-synonymous variants 87 were common and 120 and 111 were unique in $\mathrm{WoH}$ and $\mathrm{WH}$ samples, respectively (supplementary). In order to classify these variants into tissue specific (somatic) and germline, variants from control sample were considered. Out of 87 common variants in both the samples 79 variants were germline and eight were somatic (Fig. 3). WoH showed 61 germline and 59 somatic variants, whereas WH harbored 72 germline and 39 somatic variants.

These variants were then annotated against dbSNP and COSMIC databases. 194 variants from $\mathrm{WoH}$ and 184 of WH were found to be already reported in dbSNP database 
Fig. 2 Analysis workflow applied parallel to each sample involving filtering criteria; variants with a call quality $>20$ were considered as confidence variant. These confidence variants further refined to get variants occuring only in exonic and non-synonymous); functionally damaging (consequences of variation on gene and protein function with the help of bioinformatics) being considered to identify candidate causal variants and genes

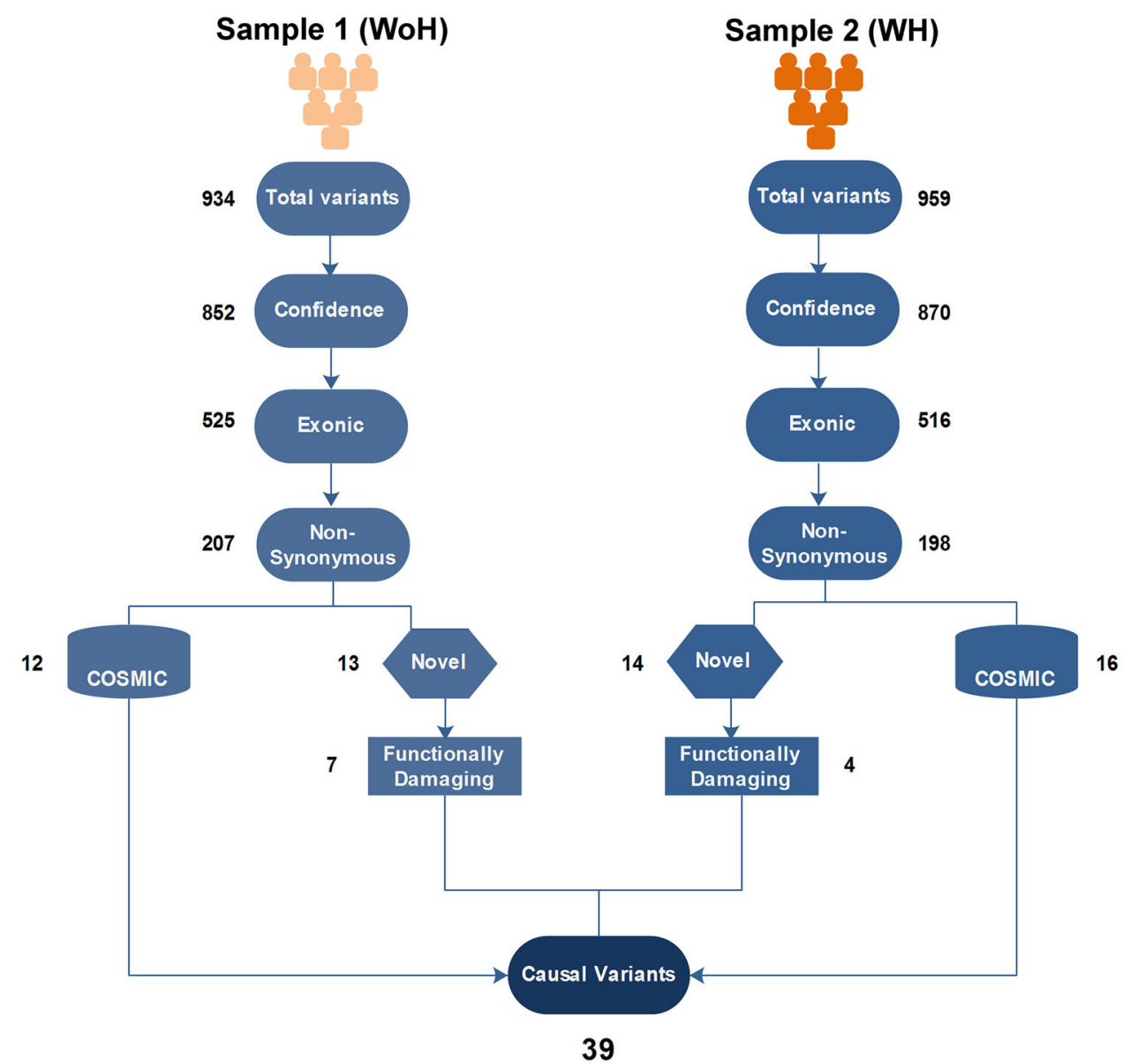

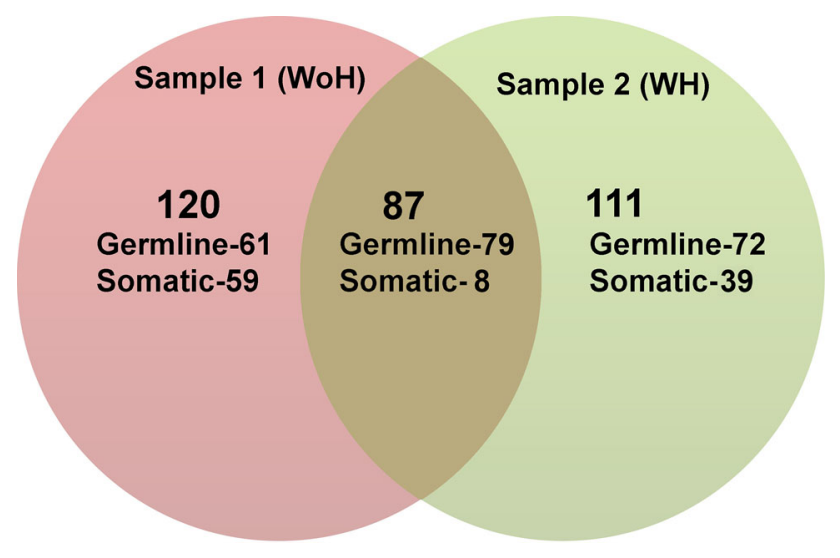

Fig. 3 Venn diagram depicting a comparative assessment of nonsynonymous variants from both the samples. Sample $1(\mathrm{red})$ and Sample 2 (green). Somatic and germline variants in each sample identified by comparing with its corresponding matched control. Variants from each samples found in matched control, were referred as germline whereas rest (sample specific variants) are considered as somatic. Each sample depicting non-habitual, habit specific (shown in green), and nonspecific (shown in brown) somatic and germline variants

(dbSNP 129). Of these, a total of 28 variants were also reported in COSMIC (Table 4). However, 27 variants could not be found in either dbSNP or COSMIC and hereafter referred to as novel. Out of the 27 novel variants, 11 were predicted to be functionally damaging as depicted from SIFT and Polyphen2. Therefore, total 39 (28 COSMIC and 11 novel functionally damaging) variants were identified as causative cancer driver variants in both samples (Table 4). WoH and WH showed 19 and 20 causative cancer driver variants, respectively. Comparative assessment revealed nine common variants in both samples, while 10 and 11 unique variants in $\mathrm{WoH}$ and $\mathrm{WH}$, respectively.

Novel variants found in COSMIC involved 17 genes in case of $\mathrm{WoH}$ and 15 in case of WH. A total of 22 unique genes were found in both $\mathrm{WoH}$ and $\mathrm{WH}$ subjects. Of which, 7 (KIT, ATM, RNF213, GATA2, DST, RET, and CYP2C19) were unique in WoH, 5 (IL7R, PKHD1, MLL3, PTPRD, and MAPK8) in WH. Genes found to be common were 10 (SETD2, ATR, CDKN2A, NCOA4, TP53, SYNE1, KAT6B, THBS1, PTPRT, and FGFR3) in both samples as shown in Fig. 4. Comparison of candidate variants and genes with two of the most comprehensive studies in HNSCC, showed no similarity at the variant level. Further six genes GATA2, IL7R, KAT6B, MAPK8, NCOA4, and SETD2 were commonly mutated in all the three datasets i.e., Agrawal, Stranskey, and this study. 
Table 3 Total number of variants and the corresponding genes, percentage of variants in the dbSNP database and there transition/transversion ratio for total and novel (not reported in COSMIC and dbSNP) variants

\begin{tabular}{lcllll}
\hline Sample & Variants & Genes & dbSNP $(\%)$ & Ti/Tv total & Ti/Tv novel \\
\hline Sample 1 $(\mathrm{WoH})$ & 934 & 280 & 96.90 & 2.51 & 1.4 \\
Sample 2 $(\mathrm{WH})$ & 959 & 275 & 95.50 & 2.61 & 1 \\
Sample 3 (control) & 1,354 & 318 & 94.30 & 2.52 \\
\hline
\end{tabular}

Assessment of mutation distribution at gene level

Average percentage mutation rate distribution shared by all detected cancer panel genes was $0.32 \%$. While, mutations shared by cancer driver genes was $0.62 \%$ in all three samples, which is almost double the average mutations harbored by all panel genes. PDE4DIP gene emerged as most mutated gene with a mutation rate of $5.86 \%$ followed by SYNE1 with a mutation rate $(3.07 \%)$ from both the samples. Other genes exhibiting highest mutation included PKHD1, LRP1B, NOTCH1, FN1, and RNF213 sharing $1.97,1.50,1.33,1.16$, and $1.16 \%$ mutations, respectively, in both samples.

\section{Discussion}

Onset and progression of cancer has been always dynamically linked with various reasons involving physical/or chemical agents, genetic v/s environment and hence is a very complex disease. In the present study, an attempt has been made to understand the genetic difference in the two different types of HNSCC subjects in the backdrop of habit (WH) and no habit (WoH). The results obtained showed distinct pattern with reference to association of genes in both set of subjects. Number of mutations observed in subjects with a habit of tobacco was more compared to number in subjects with no such habit. Association of tobacoo, alcohol, and their products in development of various cancers specially HNSCC is well studied and tobacco has several carcinogens such as Benzo[a]pyrene diol epoxide, including benzo[a]pyrene, tobacco-specific nitrosamines such as nitrosonornicotine, and reactive aldehydes such as formaldehyde etc. Some of these carcinogens like Benzo[a]pyrene diol epoxide is also linked with induction of genetic damage in the DNA (Denissenko et al. 1996).

As can be seen from Fig. 1a, b, more number of mutations were distributed on chromosomes 1, 6, and 17 . Chromosome 1 being the largest chromosome with highest number of genes attributed to highest number of mutations. Chromosome six harbors the major histocompatibility complex (Abdulla et al. 1996), and chromosome 17 genes involved in protein synthesis and gene regulation.
Although the mutations in the chromosomes are generally considered as random events but there are certain regions which are more prone to mutation such as repetitive regions. In case of chromosome 17, percentage of low copy repeats is more than $23 \%$ and hence is more prone to mutations (Stankiewicz et al. 2003; Clancy and Shaw 2008). Further, previously reported microsatellite instability and loss of heterozygosity during some cancers on chromosomes 6 and 17 (Roy et al. 2001; Amos et al. 2010; Lan et al. 2012) support the data obtained. The most promising variants were found in the $\mathrm{q}$ arm of these chromosomes. Highest mutations occurred in the 1q21 which harbor the PDE4DIP gene, 6q25 harbor the SYNE1 gene, and 17q25 harbor RNF13. Of these PDE4DIP, SYNE1, and NOTCH1 gene emerged as the genes sharing highest mutations. This clearly indicates possible role of PDE4DIP and SYNE1 genes in HNSCC in both the type of subjects i.e., with or without habits of tobacco; whereas NOTCH gene family which are mutated only in habitual subjects suggests its tobacco-dependent role.

Despite a large number of studies on genetic analysis of HNSCC (Bauman et al. 2012; Agrawal et al. 2011; Stransky et al. 2011; Poeta et al. 2007), there are no reports regarding involvement of PDE4DIP in HNSCC. Further, studies on SYNE1 in case of HNSCC are less characterized (Stransky et al. 2011) in certain populations. This could be because most of the studies are from the developed countries with different races where the genetic makeup, socioeconomic background, food habits are quite different from those of India. This explanation also holds true for nonoverlap of variants found in this study and those done in the Western countries.

The protein encoded by PDE4DIP gene serves to anchor phosphodiesterase 4D to the Golgi/centrosome region of the cell. The mutations have also been previously identified as diagnostic marker in esophageal squamous cell carcinoma (SCC) (Shimada et al. 2007). SYNE1 gene is known to be involved in nuclear polarity and spindle orientation (Luke et al. 2008) that function upstream of NOTCH1 signaling in the squamous cell differentiation pathway (Williams et al. 2011). Hence, mutations in both genes may lead to alterations in pathways of squamous cell differentiation ultimately leading to onset of HNSCC. 


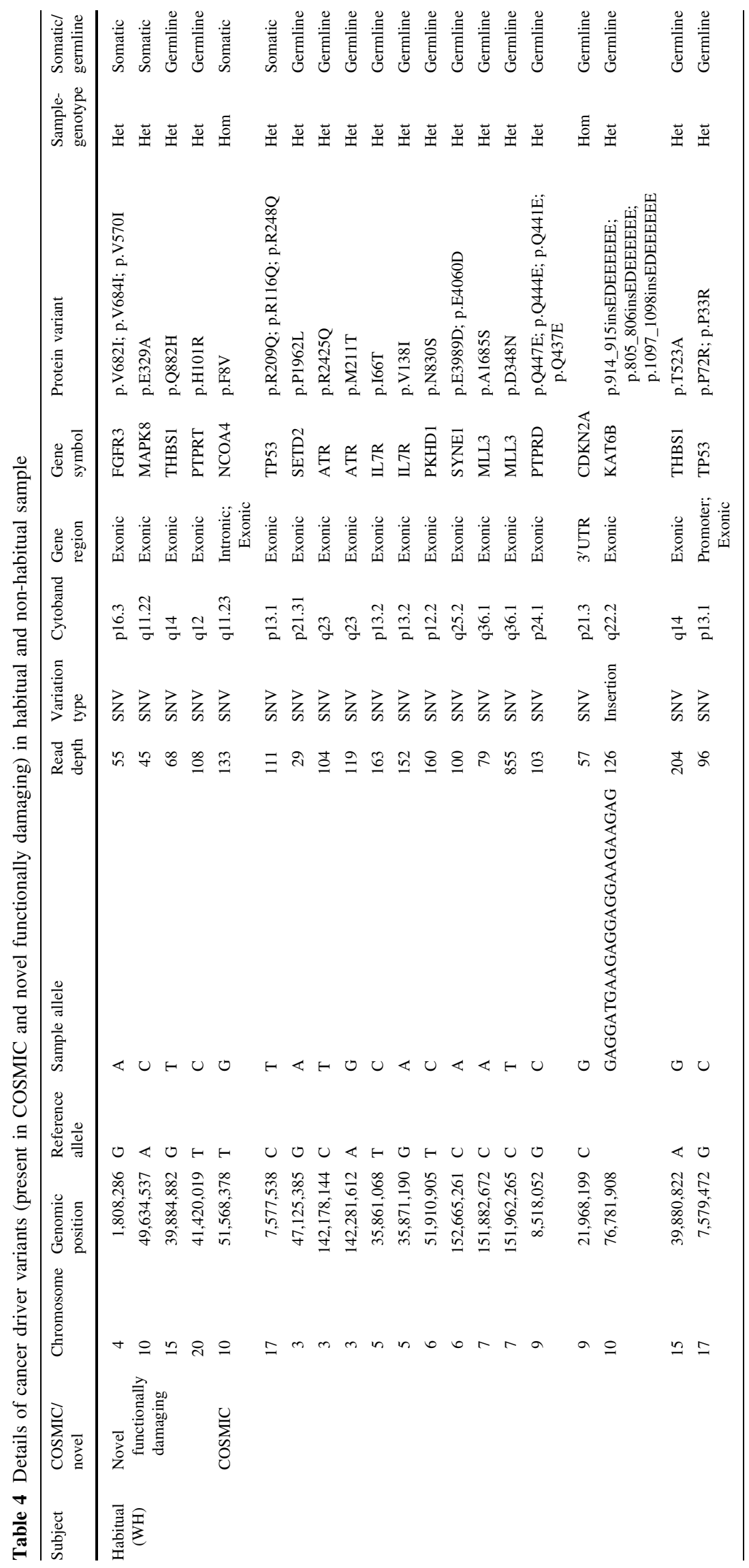




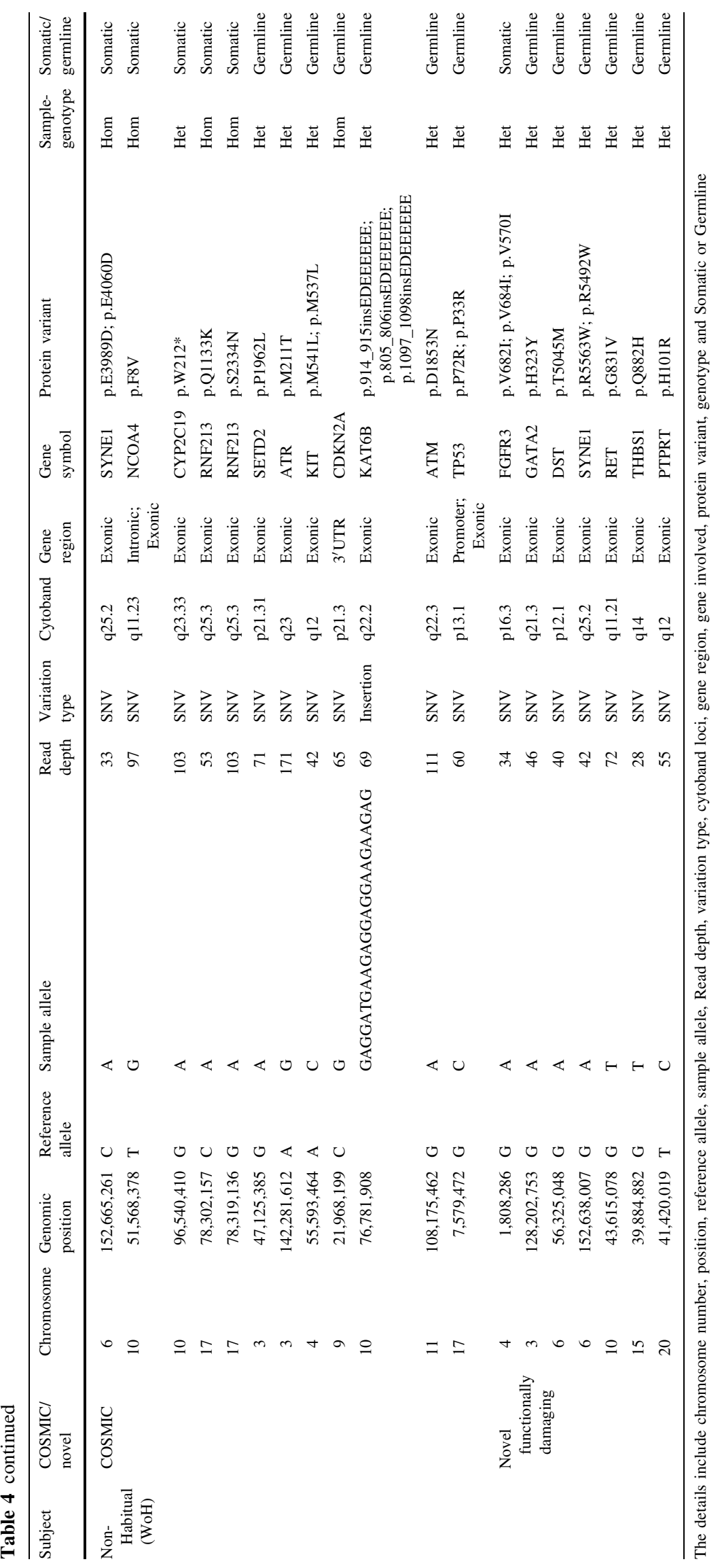




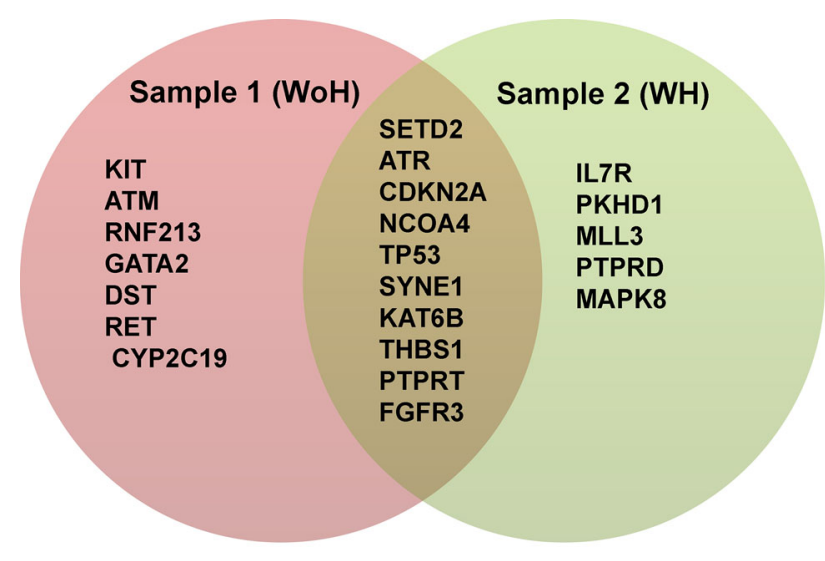

Fig. 4 Venn diagram showing cancer driver genes in each sample. Genes in red and green background are unique to non-habitual and habitual sample, respectively; genes in gray background common to both the samples

Apart from SYNE1 and PKHD1 genes which were found to be maximally mutated to 22 other genes were identified as cancer driver genes which harbor 39 variants. Out of which, 10 genes were common in both the samples while 7 and 5 genes unique to $\mathrm{WoH}$ and $\mathrm{WH}$, respectively. These genes include NCOA4, SYNE1, SETD2, ATR, CDKN2A, KAT6B, TP53, FGFR3, THBS1, and PTPRT common to both the samples whereas CYP2C19, RNF213, KIT, ATM, GATA2, DST, and RET genes unique to WoH and IL7R, PKHD1, MLL3, PTPRD, and MAPK8 unique to WH.

Of the genes commonly found in both the samples, PTPRT has been previously reported to be frequently mutated in cancer patients (Zhao et al. 2010). It supposedly regulates paxillin level which in turn affects regulation of several signaling pathways. Paxillin also regulates expression of Nesprin-3 which influences actin diamines. Since any disturbance in the regulation of actin dynamics may lead to the disformation of the core cytoskeleton PTPRT may be having a role in the disfigurement during HNSCC. Further, CDKN2A, ATR, THBS1, NCOA4, PTPRD, TP53, and ATM are known tumor suppressor genes (McLendon et al. 2008; Pardali and Moustakas 2007; Painter and Young 1980; Ligr et al. 2010; Bose et al. 2009; Kohno et al. 2010). Alteration of tumor-suppressor genes may allow cellular proliferation to continue with unregulated and autonomous, self-sufficient growth (Field et al. 1993) thereby initiating cancerous growth. Mutations in TP53 are shown to exist in over $50 \%$ of HNSCC lesions (Argiris et al. 2008) and have been shown to be one of the most common genetic abnormalities in human cancers (Field et al. 1993). NCOA4 expression studies have reported its role in oral cancer and recognized as candidate serum markers for oral squamous cell carcinomas (OSCC) (Kollara and Brown 2012). CDKN2A binds to CDK4 and
CDK6 and suppresses proliferation by inhibiting cells progressing from G1 into S phase (Liggett and Sidransky 1998), and has also been recognized as an early event in the progression of pre-malignant lesions leading to HNSCC (Schwarz et al. 2008). PTPRD is previously reported candidate tumor suppressor gene in lung cancer (Kohno et al. 2010).

Among the unique genes associated with $\mathrm{WoH}$, mutation in GATA2 has been reported to be involved in dysplasia (Fadilah et al. 2002). Similarly, DST gene is a protein coding gene required for anchoring either intermediate filaments to the actin cytoskeleton in neural and muscle cells (Dalpe et al. 1998) or keratin-containing intermediate filaments to hemidesmosomes in epithelial cells. Since HNSCC involves transformation of squamous epithelial lineage, presence of mutation in genes disrupting epithelia leading to development of cancer is justified. DNA damage sensor and control genes (ATM and ATR), (Goldgar et al. 2011; Tanaka et al. 2012) were also found to harbor mutation thereby disrupting the DNA damage control pathway. RNF213 gene is involved in the pathogenesis of moyamoya disease which has been reported to be both congenital and acquired (Sonobe et al. 2014; Mineharu et al. 2013). Actual role of this gene in HNSCC is not known but it may have a probable role in angiogenesis reported in advanced stages of cancer.

One very interesting mutation was found in the RET gene which suggests a genetic basis for development of HNSCC in WoH subjects. Mutations in RET gene are reportedly germline and has function of signaling pathway of tyrosine kinase. Further, it is also reported that specific mutations in this gene leads to development of specific tumors. For example, single point mutation at codon 918 results in Multiple Endocrine Neoplasia (Mulligan et al. 1995) and that in codon 664 lead to small cell lung carcinoma (Futami et al. 1994). In this study, we report a novel germline mutation of codon 831 which converts glycine to valine (Table 4). Functionally this mutation affects the tyrosine kinase domain of the protein thereby probably disturbing the substrate specificity. Further validation of the mutations in this gene with more subjects may provide substance to suggest a genetic basis in occurrence of HNSCC in WoH subjects.

Another important gene uniquely mutated in $\mathrm{WoH}$ was CYP2C19 gene. This gene is responsible for xenobiotic metabolism (Marzo and Balant 1996). It is also involved in the activation of different carcinogen and/or inactivation of cancer-related drugs (Antona and Sundberg 2006). Thus it may be suggested that mutations in this gene may have role in the effect of drug during therapy of HNSCC. Thus mutations in this gene may be assessed before starting a cancer treatment for effective drug effect. 
On the other hand, the unique mutated genes in $\mathrm{WH}$ subjects i.e., sample 2 included IL7R, PKHD1, MLL3, PTPRD, and MAPK8. IL7R is reported in childhood T-cell acute lymphoblastic leukemia, promotes cell transformation and tumor formation (Zenatti et al. 2011). Of these, MLL3 is a known tumor suppressor gene (Lee et al. 2009) which contributes to chromatin remodeling and transcriptional regulation in cancers (Fujimoto et al. 2012; Zang et al. 2012). It also has a key role in PI3K pathway (intracellular signaling pathway important in apoptosis), activation of which is a hallmark of a variety of malignancies, including melanoma and high-grade astrocytomas (McLendon et al. 2008; Lui et al. 2013). Additionally both IL7R and MLL3 reportedly affect histone acetyl binding (Chowdhury and Sen 2003; Li et al. 2013). Histone acetylation and deacytylation is not only important for regulation of genes involved in the genesis of cancer but also regulation of angiogenesis that permits increased tumor growth as well as the regulation of adhesion, cell migration, and invasion required for metastasis. Further, PTPRD is a known tumor suppressor for lung cancer (Kohno et al. 2010); glioblastoma (Veeriaha et al. 2009). It is a central feature in signaling cascades such as signal transducers and activators of transcription (STAT3) pathway (Veeriaha et al. 2009) involved in oncogenesis (Lui et al. 2013). Further, MAPK8 gene is known to be stimulated by tobacco smoke thereby disturbing the MAPK pathway, an important targetable pathway in HNSCC (Lui et al. 2013). PKHD1 induces cell apoptosis through PI3K and NF- $\kappa \mathrm{B}$ pathways (Sun et al. 2011).

Thus analysis of the exclusive gene mutations in the WoH subject indicates that it is the mutation in epithelial transformation and DNA damage repair genes which in turn lead to HNSCC. In view of the RNF13 gene, the study also suggests genetic origin of HNSCC. In contrast to this in case of WH subjects most of the mutations are directly in the oncogeneic genes probably because tobacco itself is carcinogenic and no hereditary basis was found.

\section{Conclusion}

Thus one can suggest that in case of non-tobacco chewers, mutation in the genes involved in squamous epithelial development and DNA repair genes lead to HNSCC, while it is the carcinogen tobacco in chewers which leads to the stimulation of various oncogenes and tumor suppressor genes leading to HNSCC. Further, presence of novel mutations not reported earlier in HNSCC patients also suggest that Indian sub-continent may have different sets of genes, as compared to other parts of the world, involved in the development and progression of HNSCC. However, we need to strengthen the statements by further sequencing of the subset of the shortlisted genes from each sample on a larger sample patient's population.

Acknowledgments This work was supported by the Department of Science and Technology, Government of Gujarat, under Project-151 and BioBank Project.

Conflict of interest The authors declare that they have no conflict of interest.

Open Access This article is distributed under the terms of the Creative Commons Attribution License which permits any use, distribution, and reproduction in any medium, provided the original author(s) and the source are credited.

\section{References}

Abdulla S, Alderton RP, Glynne RJ, Gut IG, Hosking LK, Jackson A, Kelly A, Newell WR, Radley E, Sanseau P, Thorpe KL, Trowsdale J, Beck S (1996) DNA sequencing of the MHC class II region and the chromosome 6 sequencing effort at the Sanger Centre. DNA Seq 7:5-7

Agrawal N, Frederick MJ, Pickering CR et al (2011) Exome sequencing of head and neck squamous cell carcinoma reveals inactivating mutations in NOTCH1. Science 333:1154-1157. doi:10.1126/science.1206923

Amos CI, Pinney SM, Li Y, Kupert E (2010) A susceptibility locus on chromosome $6 \mathrm{q}$ greatly increases lung cancer risk among light and never smokers. Cancer Res 70:2359-2367. doi:10.1158/0008-5472

Antona CR, Sundberg MI (2006) Cytochrome P450 pharmacogenetics and cancer. Oncogene 25:1679-1691

Argiris A, Karamouzis MV, Raben D (2008) Head and neck cancer. Lancet 371(9625):1695-1709

Bamford S, Dawson E, Forbes S, Clements J, Pettett R, Dogan A, Flanagan A, Teague J, Futreal PA, Stratton MR, Wooster R (2004) The COSMIC (Catalogue of Somatic Mutations in Cancer) database and website. Br J Cancer 91(2):355-358

Bauman JE, Michel LS, Chung CH (2012) New promising molecular targets in head and neck squamous cell carcinoma. Curr Opin Oncol 24:235-242. doi:10.1097/CCO.0b013e3283517920

Bose S, Yap LF, Fung M, Starzcynski J, Saleh A, Morgan S, Dawson C, Chukwuma MB, Maina E, Buettner M, Wei W, Arrand J, Lim PV, Young LS, Teo SH, Stankovic T, Woodman CB, Murray PG (2009) The ATM tumour suppressor gene is down-regulated in EBV-associated nasopharyngeal carcinoma. J Pathol 217:345-352. doi:10.1002/path.2487

Chowdhury D, Sen R (2003) Transient IL-7/IL-7R signaling provides a mechanism for feedback inhibition of immunoglobulin heavy chain gene rearrangements. Immunity 18:229-241

Clancy S, Shaw K (2008) DNA deletion and duplication and the associated genetic disorders. Nat Edu 1:23

Dalpe G, Leclerc N, Vallee A, Messer A, Mathieu M, De Repentigny Y, Kothary R (1998) Dystonin is essential for maintaining neuronal cytoskeleton organization. Mol Cell Neurosci 10(5-6):243-257

Denissenko MF, Pao A, Tang M, Pfeifer GP (1996) Preferential formation of benzo[a]pyrene adducts at lung cancer mutational hotspots in P53. Science 274:430-432

Fadilah S, Cheong SK, Roslan H, Rozie HM (2002) GATA-1 and GATA-2 gene expression is related to the severity of dysplasia in myelodysplastic syndrome. Leukemia 16:1563-1565

Ferlay J, Shin HR, Bray F (2010) GLOBOCAN 2008, cancer incidence and mortality worldwide in IARC Cancer Base No. 10. 
International Agency for Research on Cancer [http://www. globocan.iarc.fr]

Field JK, Pavelic ZP, Spandidos DA, Stambrook PJ, Jones AS, Gluckman JL (1993) The role of the p53 tumor suppressor gene in squamous cell carcinoma of the head and neck. Arch Otolaryngol Head Neck Surg 119:1118-1122

Fujimoto A, Totoki Y, Abe T, Boroevich KA, Hosoda F, Nguyen HH (2012) Whole-genome sequencing of liver cancers identifies etiological influences on mutation patterns and recurrent mutations in chromatin regulators. Nat Genet 44:760-764. doi:10. 1038/ng.2291

Futami H, Egawa S, Yamaguchi K (1994) A novel point mutation of the RET proto-oncogene in small cell lung carcinoma cell lines. Proc Jpn Acad 70B:210-214

Goldgar DE, Healey S, Dowty JG, Silva LD, Chen X, Spurdle AB, Terry MB, Daly MJ, Buys SM, Southey MC, Andrulis I, Esther MJ, Khanna KK, Hopper JL, Peter JO, Lakhani S, Trench GC (2011) Rare variants in the ATM gene and risk of breast cancer. Breast Cancer Res 13:R73. doi:10.1186/bcr2919

Imyanitov EN, Togo AV, Hanson KP (2004) Searching for cancerassociated gene polymorphisms: promises and obstacles. Cancer Lett 204:3-14

Kalavrezos N, Yelensky R, Beck S, Stephens PJ, Boshoff C, Liu Q, Guo Y, Shyr Y (2012) Steps to ensure accuracy in genotype and SNP calling from Illumina sequencing data. BMC Genom 13(Suppl 8):S8. doi:10.1186/1471-2164-13-S8-S8

Kohno T, Otsuka A, Girard L, Sato M, Iwakawa R, Ogiwara H, Sanchez-Cespedes M, Minna JD, Yokota J (2010) A catalog of genes homozygously deleted in human lung cancer and the candidacy of PTPRD as a tumor suppressor gene. Gene Chromosom Canc 49:342-352. doi:10.1002/gcc.20746

Kollara A, Brown TJ (2012) Expression and function of nuclear receptor co-activator 4: evidence of a potential role independent of co-activator activity. Cell Mol Life Sci 69:3895-3909

Lan Q, Hsiung CA, Matsuo K (2012) Genome-wide association analysis identifies new lung cancer susceptibility loci in neversmoking women in Asia. Nat Genet 44:1330-1335. doi:10.1038/ ng. 2456

Lechner M, Frampton GM, Fenton T, Feber A, Palmer G, Jay A, Pillay N, Forster M, Cronin MT, Lipson D, Miller VA, Brennan TA, Henderson S, Vaz F, Flynn PO, Kalavrezos N, Teschendorff AE, Boshoff C, Beck S (2013) Identification and functional validation of HPV-mediated hypermethylation in head and neck squamous cell carcinoma. Genome Med 5:15. doi:10.1186/gm419

Lee J, Kim DH, Lee S, Yang QH, Lee DK (2009) A tumor suppressive coactivator complex of p53 containing ASC-2 and histone H3-lysine-4 methyltransferase MLL3 or its paralogue MLL4. Proc Natl Acad Sci 106:8513-8518. doi:10.1073/pnas. 0902873106

Li WD, Li QR, Xu SN, Wei FJ, Ye ZJ, Cheng JK, Chen JP (2013) Exome sequencing identifies an MLL3 gene germ line mutation in a pedigree of colorectal cancer and acute myeloid leukemia. Blood 121(8):1478-1479. doi:10.1182/blood-2012-12-470559

Liggett WH Jr, Sidransky D (1998) Role of the p16 tumor suppressor gene in cancer. J Clin Oncol 16:1197-1206

Ligr M, Li Y, Zou X, Daniels G, Melamed J, Peng Y, Wang W, Wang J, Ostrer H, Pagano M, Wang Z, Garabedian MJ, Lee P (2010) Tumor suppressor function of androgen receptor coactivator ARA70alpha in prostate cancer. Am J Pathol 176:1891-1900. doi:10.2353/ajpath.2010.090293

Lui VW, Hedberg ML, Li H, Vangara BS, Pendleton K, Zeng Y, Lu Y, Zhang Q, Du Y, Gilbert BR, Freilino M, Sauerwein S, Peyser ND, Xiao D, Diergaarde B, Wang L, Chiosea S, Seethala R, Johnson JT, Kim S, Duvvuri U, Ferris RL, Romkes M, Nukui T, Kwok-Shing Ng P, Garraway LA, Hammerman PS, Mills GB, Grandis JR (2013) Frequent mutation of the PI3K pathway in head and neck cancer defines predictive Biomarkers. Cancer Discov 3(7):761-769. doi:10.1158/2159-8290.CD-13-0103

Luke Y, Hafida Z, Iakowos K, Verena MJ, Lorenz S, Wenshu L, Maria S, Sascha N, Asa B, Martina M, Padmakumar VC, Joachim G, Gerd W, Angelika AN (2008) Nesprin-2 Giant (NUANCE) maintains nuclear envelope architecture and composition in skin. J Cell Sci 121:1887-1898. doi:10.1242/jcs. 019075

Marzo A, Balant LP (1996) Investigation of xenobiotic metabolism by CYP2D6 and CYP2C19: importance of enantioselective analytical methods. J Chromatogr B 1:73-92

McLendon R, Friedman A, Bigner D, Van Meir EG et al (2008) Comprehensive genomic characterization defines human glioblastoma genes and core pathways. Nature 455:1061-1068. doi:10.1038/nature07385

Mineharu Y, Takagi Y, Takahashi JC, Hashikata H, Liu W, Hitomi T, Kobayashi H, Koizumi A, Miyamoto S (2013) Rapid progression of unilateral moyamoya disease in a patient with a family history and an RNF213 risk variant. Cerebrovasc Dis 36(2):155-157

Mulligan LM, Marsh DJ, Robinson BG (1995) Genotype-phenotype correlation in MEN 2: report of the international RET mutation consortium. J Intern Med 238:343-346

Painter RB, Young BR (1980) Radiosensitivity in ataxia-telangiectasia: a new explanation. Proc Natl Acad Sci 77:7315-7317

Pardali K, Moustakas A (2007) Actions of TGF-beta as tumor suppressor and pro-metastatic factor in human cancer. Biochim Biophys Acta 1775:21-62

Poeta ML, Manola J, Goldwasser MA (2007) TP53 mutations and survival in squamous-cell carcinoma of the head and neck. N Engl J Med 357:2552-2561

Rodriguez T, Altieri A, Chatenoud L, Gallus S, Bosetti C, Negri E, Franceschi S, Levi F, Talamini R, La Vecchia C (2004) Risk factors for oral and pharyngeal cancer in young adults. Oral Oncol 40:207-213

Roy D, Calaf G, Hei TK (2001) Frequent allelic imbalance on chromosome 6 and 17 correlate with radiation-induced neoplastic transformation of human breast epithelial cells. Carcinogenesis 22:1685-1692

Schwarz S, Bier J, Driemel O, Reichert TE, Hauke S, Hartmann A, Brockhoff $G$ (2008) Losses of 3p14 and 9p21 as shown by fluorescence in situ hybridization are early events in tumorigenesis of oral squamous cell carcinoma and already occur in simple keratosis. Cytometry A 73:305-311. doi:10.1002/cyto.a.20504

Sherry ST, Ward MH, Kholodov M, Baker J, Phan L, Smigielski EM, Sirotkin K (2001) dbSNP: the NCBI database of genetic variation. Nucleic Acids Res 29(1):308-311

Shimada H, Kuboshima M, Shiratori T, Nabeya Y, Takeuchi A, Takagi H, Nomura F, Takiguchi M, Ochiai T, Hiwasa T (2007) Serum anti-myomegalin antibodies in patients with esophageal squamous cell carcinoma. Int J Oncol 30:97-103.7

Sonobe S, Fujimura M, Niizuma K, Nishijima Y, Ito A, Shimizu H, Kikuchi A, Arai-Ichinoi N, Kure S, Tominaga T (2014) Temporal profile of the vascular anatomy evaluated by 9.4-T magnetic resonance angiography and histopathological analysis in mice lacking RNF213: a susceptibility gene for moyamoya disease. Brain Res 1552:64-71

Stankiewicz P, Shaw CJ, Dapper JD, Wakui K, Shaffer LG, Withers M, Elizondo L, Park SS, Lupski JR (2003) Genome architecture catalyzes nonrecurrent chromosomal rearrangements. Am J Hum Genet 72:1101-1116

Stransky N, Egloff AM, Tward AD, Kostic AD, Cibulskis K, Sivachenko A (2011) The mutational landscape of head and neck squamous cell carcinoma. Science 333:1157-1160. doi:10.1126/ science. 1208130

Subramanian J, Govindan R (2007) Lung cancer in never smokers: a review. J Clin Oncol 25:561-570 
Sun L, Wang S, Hu C, Zhang X (2011) Down-regulation of PKHD1 induces cell apoptosis through PI3K and NF- $\mathrm{BB}$ pathways. Exp Cell Res 317(7):932-940. doi:10.1016/j.yexcr.2011.01.025

Tanaka A, Weinel S, Nagy N, Odriscoll M, Lai-Cheong JE, KulpShorten CL, Knable A, Carpenter G, Fisher SA, Hiragun M, Yanase Y, Hide M, Callen J, McGrath JA (2012) Germline mutation in ATR in autosomal- dominant oropharyngeal cancer syndrome. Am J Hum Genet 90(3):511-517. doi:10.1016/j.ajhg. 2012.01.007

Veeriaha S, Brennanb C, Menga S, Singhc B, Fagina JA, Solita DB, Patyc PB, Rohlea D, Vivancoa I, Chmieleckia J, Paoa W, Ladanyia M, Geralda WL, Liauf L, Cloughesyf TC, Mischelf PS, Sanderg C, Taylorg B, Schultzg N, Majorg J, Heguya A, Fanga F, Mellinghoffa IK, Chana TA (2009) The tyrosine phosphatase PTPRD is a tumor suppressor that is frequently inactivated and mutated in glioblastoma and other human cancers. PNAS 106(23):9435-9440. doi:10.1073/pnas.0900571106

Williams SE, Beronja S, Pasolli HA, Fuchs E (2011) Asymmetric cell divisions promote Notch-dependent epidermal differentiation. Nature 470(7334):353-358. doi:10.1038/nature09793

Zang ZJ, Cutcutache I, Poon SL, Zhang SL, McPherson JR, Tao J (2012) Exome sequencing of gastric adenocarcinoma identifies recurrent somatic mutations in cell adhesion and chromatin remodeling genes. Nat Genet 44:570-574. doi:10.1038/ng.2246

Zeka A, Gore R, Kriebel D (2003) Effects of alcohol and tobacco on aero digestive cancer risks: a meta-regression analysis. Cancer Causes Control 14:897-906

Zenatti PP, Ribeiro D, Li W, Zuurbier L, Silva MC, Paganin M, Tritapoe J, Hixon JA, Silveira AB, Cardoso BA, Sarmento LM, Correia N, Toribio ML, Kobarg J, Horstmann M, Pieters R, Brandalise SR, Ferrando AA, Meijerink JP, Durum SK, Yunes JA, Barata JT (2011) Oncogenic IL7R gain-of-function mutations in childhood T-cell acute lymphoblastic leukemia. Nat Genet 43(10):932-939. doi:10.1038/ng.924

Zhao Y, Zhang X, Guda K, Lawrence E, Sun Q, Watanabe T, Iwakura Y, Asano M, Wei L, Yang Z, Zheng W, Dawson D, Willis J, Markowitz SD, Satake M, Wang Z (2010) Identification and functional characterization of paxillin as a target of protein tyrosine phosphatase receptor T. Proc Natl Acad Sci USA 107:2592-2597. doi:10.1073/pnas.0914884107 